Canadian

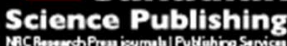

Applied Physiology, Nutrition, and Metabolism Physiologie appliquée, nutrition et métabolisme

\title{
ENDOTHELIAL VASODILATOR FUNCTION IN NORMAL WEIGHT ADULTS WITH METABOLIC SYNDROME
}

\begin{tabular}{|r|l|}
\hline Journal: & Applied Physiology, Nutrition, and Metabolism \\
\hline Manuscript ID & apnm-2016-0171.R1 \\
\hline Manuscript Type: & Article \\
\hline Date Submitted by the Author: & 09-May-2016 \\
\hline Complete List of Authors: & $\begin{array}{l}\text { Dow, Caitlin; University of Colorado, Integrative Physiology } \\
\text { Lincenberg, Grace; University of Colorado, Integrative Physiology } \\
\text { Greiner, Jared; University of Colorado, Integrative Physiology } \\
\text { Stauffer, Brian; University of Colorado, Medicine } \\
\text { DeSouza, Christopher; University of Colorado, Integrative Physiology }\end{array}$ \\
\hline Keyword: & $\begin{array}{l}\text { endothelium, vasodilation, forearm blood flow, metabolic syndrome, } \\
\text { normal weight }\end{array}$ \\
\hline
\end{tabular}




\section{ENDOTHELIAL VASODILATOR FUNCTION IN NORMAL WEIGHT ADULTS WITH METABOLIC SYNDROME}

Caitlin A. Dow, PhD ${ }^{\mathrm{a}}$, Grace M. Lincenberg, MS ${ }^{\mathrm{a}}$, Jared J. Greiner, MS ${ }^{\mathrm{a}}$, Brian L. Stauffer, $\mathrm{MD}^{\mathrm{a}, \mathrm{b}, \mathrm{c}}$, and Christopher A. DeSouza, $\mathrm{PhD}^{\mathrm{a}}$

${ }^{a}$ Integrative Vascular Biology Laboratory, Department of Integrative Physiology, University of Colorado, Boulder, CO 80309, ${ }^{b}$ Department of Medicine, University of Colorado Denver and the Health Sciences Center, ${ }^{c}$ Aurora, CO 80045, Denver Health Medical Center, Denver, CO 80204

Correspondence: Christopher DeSouza, Ph.D.

Integrative Vascular Biology Laboratory

Department of Integrative Physiology

University of Colorado

Clare Small rm. 114

1725 Pleasant St.

Boulder, CO 80309

TEL: $\quad+1$ (303) 492-2988

FAX: +1 (303) 492-6778

EMAIL: Christopher.Desouza@colorado.edu 


\begin{abstract}
Metabolic Syndrome (MetS) typically presents with obesity; however, obesity is not a requisite characteristic for MetS classification and related vascular risk. We tested the hypothesis that MetS, independent of excess adiposity, is associated with impaired endothelial vasodilator dysfunction. Thirty-two sedentary, middle-aged adults were studied: 11 normal weight (9 M/2 F; BMI $\left.24.0 \pm 0.3 \mathrm{~kg} / \mathrm{m}^{2}\right) ; 11$ normal weight with MetS (9 M/2 F; $\left.24.7 \pm 0.3 \mathrm{~kg} / \mathrm{m}^{2}\right)$; and 10 obese without MetS (8 M/2 F; $\left.31.4 \pm 0.5 \mathrm{~kg} / \mathrm{m}^{2}\right)$. MetS was established according to NCEP ATP III criteria. Forearm blood flow (FBF) responses to intra-arterial infusions of acetylcholine and sodium nitroprusside were measured via strain-gauge plethysmography. FBF responses to acetylcholine were $\sim 20 \%$ lower $(\mathrm{P}<0.05)$ in the normal weight with MetS (from $4.0 \pm 0.3$ to $13.0 \pm 1.0 \mathrm{~mL} / 100 \mathrm{~mL}$ tissue $/ \mathrm{min}$ ) and obese (from $4.8 \pm 0.2$ to $12.2 \pm 1.1 \mathrm{~mL} / 100 \mathrm{~mL}$ tissue $/ \mathrm{min}$ ) compared with normal weight (from $4.6 \pm 0.4$ to $15.8 \pm 0.7 \mathrm{~mL} / 100 \mathrm{~mL}$ tissue/min) subjects. Of note, FBF responses to acetylcholine were similar between the normal weight with MetS and obese adults. There were no differences in FBF response to sodium nitroprusside between groups. These data indicate that the presence of MetS, independent of obesity, is associated with diminished endothelium-dependent vasodilation. Endothelial vasodilator dysfunction may underlie the increased cardiovascular risk in normal weight adults with MetS.
\end{abstract}

Keywords: endothelium, vasodilation, forearm blood flow, metabolic syndrome, normal weight 


\section{INTRODUCTION}

Metabolic Syndrome (MetS) refers to a clustering of risk factors including dyslipidemia, prehypertension, hyperglycemia, and central adiposity that appear together and ultimately accelerate the development of atherothrombotic cardiovascular disease (CVD) (Grundy 2002; Ingelsson et al. 2007). MetS typically presents with obesity; however, data from the National Health and Nutrition Examination Survey (NHANES) indicates that obesity is not a prerequisite for the development of MetS (Park et al. 2003; Ervin 2009). Nearly $10 \%$ of adults in the United States with a normal body mass index (BMI) are reported to have MetS (Ervin 2009). Importantly, normal weight adults with MetS are at an increased risk of CVD morbidity and mortality compared with metabolically healthy normal weight adults (Fan et al. 2013; Yoo et al. 2014). The mechanisms responsible for the elevated risk for CVD in normal weight adults with MetS are not completely understood, but likely extend beyond the constellation of traditional risk factors comprising MetS (Du et al. 2015; Yoo et al. 2015).

Impaired endothelium-dependent vasodilation, a hallmark characteristic of endothelial dysfunction, is an underlying factor in the pathogenesis of CVD (Quyyumi 1998; Campia et al. 2012). Endothelium-dependent vasodilation is markedly impaired in obese adults with MetS compared with metabolically healthy obese adults (Schinzari et al. 2015). This finding underscores the role of MetS, above and beyond that of excess adiposity alone, in endothelial vasodilator dysfunction. However, the influence of MetS, independent of obesity, on endothelium-dependent vasodilation is currently unknown. Endothelial vasodilator dysfunction may be a contributing factor to the increased CVD risk in normal weight adults with MetS. 
Accordingly, we tested the hypothesis that endothelium dependent vasodilation is impaired in normal weight adults with MetS compared with normal weight adults without MetS. To address this aim, we used an isolated forearm model to assess endothelial vasodilator function in metabolically healthy normal weight adults and normal weight adults with MetS.

\section{METHODS AND PROCEDURES}

Subjects. Thirty-two sedentary, middle-aged adults were studied: 11 normal weight without MetS (age 55 $\pm 2 \mathrm{yr} ; 9 \mathrm{M} / 2 \mathrm{~F}) ; 11$ normal weight with MetS (56 $\pm 3 \mathrm{yr} ; 9$ $\mathrm{M} / 2 \mathrm{~F}$ ); and 10 obese without MetS (56 $\pm 2 \mathrm{yr} ; 8 \mathrm{M} / 2 \mathrm{~F}$ ). All normal weight adults had a BMI $<26.0 \mathrm{~kg} / \mathrm{m}^{2}$ whereas all obese adults had a BMI $\geq 30.0 \mathrm{~kg} / \mathrm{m}^{2}$. MetS was established according to the National Cholesterol Education Program (NCEP) Adult Treatment Plan (ATP) III criteria (Expert Panel on Detection and Treatment of High Blood Cholesterol in 2001). All subjects were nonsmokers, non-medicated (including vitamins), and free of overt CVD as assessed by medical history, physical examination, resting and exercise electrocardiograms, and fasting blood chemistries. Women were at least one year postmenopausal and had never taken or discontinued hormone replacement therapy at least one year prior to study start. The Institutional Review Board at the University of Colorado, Boulder, approved the study. All subjects provided written informed consent according to University guidelines.

Body Composition. Body mass was measured to the nearest 0.1 kilogram using a medical beam balance (Detecto, Webb City, MO) and height was measured to the nearest centimeter. BMI was calculated as weight (kilograms) divided by height (meters) squared. Minimal waist circumference was measured according to published guidelines 
(Lohman et al. 1988). Percent body fat was determined by dual-energy X-ray absorptiometry (Lunar Radiation, Madison, WI).

Metabolic Measures. Fasting plasma lipid, lipoprotein, glucose, and insulin concentrations were determined using standard techniques (Van Guilder et al. 2008a) by the clinical laboratory at the Clinical and Translational Research Center at the University of Colorado, Boulder. Insulin resistance was estimated using the homeostasis model of assessment (HOMA-IR) (Matthews et al. 1985).

Intra-arterial Infusion Protocol. All measurements were performed in a temperature-controlled room between 7 and 10 AM after a 12-hour overnight fast as previously described (Hoetzer et al. 2003). Briefly, a 5-cm, 20-gauge catheter was inserted into the brachial artery of the non-dominant arm under local anesthesia (1\% lidocaine). Forearm blood flow (FBF) was measured using strain-gauge venous occlusion plethysmography (D.E. Hokanson, Bellevue, WA). Following the measurement of resting blood flow for five minutes, acetylcholine was infused intra-arterially at rates of 4.0, 8.0 and $16.0 \mu \mathrm{g} / 100 \mathrm{~mL}$ tissue/min and sodium nitroprusside at 1.0, 2.0 and $4.0 \mu \mathrm{g} / 100 \mathrm{~mL}$ tissue/min for five minutes at each dose.

Statistical Analysis. Differences in subject characteristics and area under the curve data were determined by one-way analysis of variance (ANOVA). Group differences in the FBF responses to each vasoactive drug were determined by repeated measures ANOVA. Post hoc testing using Newman-Keuls method was performed to determine within group differences at each concentration. Simple and forward stepwise multiple regression analyses were used to determine the relations between the outcome variables and variables of interest. Although the number of women in the study was 
small, their values were almost identical to the men. As such, the data were pooled and presented together. All values are expressed as mean \pm SEM. Statistical significance was set a priori at $\mathrm{P}<0.05$.

\section{RESULTS}

Select subject characteristics are presented in the Table. Body mass, BMI, percent body fat, and waist circumference were higher in the obese compared with the normal weight and normal weight with MetS groups. MetS component variables were significantly higher in the normal weight with MetS compared with the normal weight group, specifically: systolic blood pressure, triglycerides, and glucose, whereas HDLcholesterol was significantly lower. Triglyceride and glucose concentrations were higher in the normal weight with MetS compared with the obese group. Insulin concentrations were significantly higher in the obese group compared with both normal weight groups, while HOMA-IR was significantly higher in the normal weight with MetS and obese groups compared with the normal weight group.

Figure 1 shows the FBF response to acetylcholine and sodium nitroprusside. FBF to acetylcholine was significantly blunted $(\sim 20 \%$; $<<0.05)$ in the normal weight with MetS group (from $4.0 \pm 0.3 \mathrm{~mL} / 100 \mathrm{~mL}$ tissue/min to $13.0 \pm 0.9 \mathrm{~mL} / 100 \mathrm{~mL}$ tissue $/ \mathrm{min}$ ) compared with normal weight controls (from $4.6 \pm 0.4 \mathrm{~mL} / 100 \mathrm{~mL}$ tissue/min to $15.8 \pm 0.7$ $\mathrm{mL} / 100 \mathrm{~mL}$ tissue/min). The FBF response to acetylcholine in the normal weight with MetS group was not significantly different from the obese group (from $4.8 \pm 0.2 \mathrm{~mL} / 100$ $\mathrm{mL}$ tissue/min to $12.2 \pm 1.1 \mathrm{~mL} / 100 \mathrm{~mL}$ tissue/min). Total $\mathrm{FBF}$ to acetylcholine (area under the curve) was approximately $30 \%$ lower $(\mathrm{P}<0.05)$ in the normal weight with MetS 
$(55.2 \pm 8.4 \mathrm{~mL} / 100 \mathrm{~mL}$ tissue $)$ and obese $(52.4 \pm 7.9 \mathrm{~mL} / 100 \mathrm{~mL}$ tissue $)$ groups compared with the normal weight controls $(78.5 \pm 6.5 \mathrm{~mL} / 100 \mathrm{~mL}$ tissue). There were no significant differences $(\mathrm{P}=0.45)$ in the vasodilator response to sodium nitroprusside between groups.

In the normal weight subjects (with and without MetS), peak FBF response to acetylcholine was inversely and significantly associated with fasting plasma glucose and systolic blood pressure (Figure 2). Stepwise regression analysis revealed that fasting plasma glucose was the primary determinant of the vasodilator response to acetylcholine, accounting for $35 \%$ of the variability $\left(\mathrm{R}^{2}=0.35 ; \beta=-0.162\right)$. Aside from fasting plasma glucose and systolic blood pressure, there were no significant correlations between the vasodilation to acetylcholine and other anthropometric, hemodynamic or metabolic variables.

\section{DISCUSSION}

The primary new finding of the present study is that endothelium-dependent vasodilation is impaired in normal weight adults with MetS compared with normal weight adults without MetS. Moreover, the degree of impairment in endothelial vasodilator function in normal weight adults with MetS is similar to that of obese adults without MetS.

MetS confers significant increase in CVD risk. A meta-analysis involving nearly 1 million adults concluded that the presence of MetS is associated with a two-fold increased risk for CVD, myocardial infarction and stroke (Mottillo et al. 2010). Classically, MetS presents with excess adiposity (Despres and Lemieux 2006) exacerbating CVD risk with obesity (Grundy 2004). The mechanisms underlying the 
increased CV risk with MetS are not fully understood, but endothelial dysfunction is considered a primary contributing factor (Suzuki et al. 2008). In obese adults with MetS, endothelial vasomotor function, a key feature of endovascular health, is negatively affected (Schinzari et al. 2010; Rocha et al. 2014; Schinzari et al. 2015). For example, Schinzari, et al. (Schinzari et al. 2015) demonstrated that endothelium-dependent vasodilator dysfunction is worse in obese adults with MetS than obese adults without MetS. Moreover, we recently demonstrated (Rocha et al. 2014) that MetS is associated with higher endothelin-1-mediated vasoconstrictor tone in obese adults. The results of the present study significantly extend these findings by demonstrating that endotheliumdependent vasodilation is markedly reduced in normal weight adults with MetS. Indeed, the forearm vasodilator response to the endothelial agonist acetylcholine was $\sim 30 \%$ lower in the normal weight MetS group compared with the normal weight group without MetS. Thus, the negative influence of MetS on endothelial vasodilator capacity is not limited to obese adults. Reduction in endothelium-dependent vasodilation occurs early in atherogenesis before histological or angiographic evidence of disease (Yasue et al. 1990) and may thus contribute to MetS-related increased cardiovascular risk (Suzuki et al. 2008).

An interesting finding of the present study is that endothelial vasodilator function was almost identical between the normal weight group with MetS and the obese adults free of MetS despite marked anthropometric group differences in body mass, BMI, body fat percentage and waist circumference. Consistent with previous studies (Van Guilder et al. 2008b; Han et al. 2011), we demonstrate that endothelium-dependent vasodilation is significantly blunted in obese adults free of other cardiometabolic risk factors. The 
presence of the MetS syndrome in normal weight adults appears to render an endovascular phenotype similar to obesity per se. It is interesting to note that although the normal weight/MetS subjects in the present study presented hemodynamic and metabolic characteristics that met MetS criteria, their respective laboratory values were not grossly abnormal and none of the subjects were hypertensive or diabetic. Thus, even a modest cardiometabolic MetS profile is associated with profound endothelial vasodilator dysfunction. Considering $\sim 10 \%$ of normal weight adults in the United States have MetS (Ervin 2009), continued clinical vigilance for, and treatment of, MetS regardless of body composition status is important for CVD prevention especially in middle-aged and older adults.

The mechanisms underlying the impairment in endothelium-mediated vasodilation associated with the normal weight MetS phenotype are unclear. It is experimentally difficult in clinical studies to tease out whether the MetS-related dysfunction is due to an individual component of the syndrome or a constellation of factors. In the present study, systolic blood pressure and fasting glucose concentrations were inversely correlated with peak forearm blood flow to acetylcholine in normal weight groups, suggesting both as putative mediators underlying the differences in vasodilation. This notion is supported by previous studies demonstrating that elevations in systolic blood pressure and blood glucose concentrations, independently (Vehkavaara et al. 1999; Plavnik et al. 2007; Weil et al. 2011) and combined (Ghiadoni et al. 2008), negatively influence endothelium-dependent vasodilation. Although not measured herein, MetS has been shown to adversely influence nitric oxide bioavailability (Tesauro et al. 2005; Schinzari et al. 2013) and endothelin-1 mediated vasoconstriction in obese adults (Rocha 
et al. 2014; Schinzari et al. 2015). It is possible that the MetS-related diminution in endothelium-dependent vasodilation in normal weight adults may be due to dysregulation of the nitric oxide and endothelin-1 systems. Considering that both blood pressure (Weil et al. 2011; Weil et al. 2012) and glucose concentrations (Ihlemann et al. 2003; Diehl et al. 2013) also independently affect nitric oxide bioavailability and endothelin-1 system activity, these mechanisms are certainly plausible and reasonable areas for future studies.

There are two important experimental considerations regarding this study that merit mention. Firstly, this study was cross-sectional in nature; thus, lifestyle and genetic factors may have influenced our results. In an effort to minimize the effects of lifestyle, all subjects were sedentary, nonsmokers who were not taking any medication including vitamin supplements that could influence endothelium-dependent vasodilation.

Secondly, the small number of women in the study precludes us from definitively addressing possible gender interactions/differences with MetS-related endothelial vasodilator dysfunction. Relatedly, we acknowledge the modest overall sample size of the study. However, the employment of strict inclusion criteria to limit confounding variables and the robust differences in blood flow observed between the normal weight groups resulted in sufficient statistical power (determined post-hoc; $80 \%$ power; effect size 1.12) to assess group-differences with minimal risk of committing a type-II error.

\section{CONCLUSION}

In conclusion, the results of the present study demonstrate that the presence of MetS independent of excess adiposity is associated with diminished endotheliumdependent vasodilation. Endothelial vasodilator dysfunction may contribute to the 
increased cardiovascular risk reported in normal weight adults with MetS.

\section{CONFLICTS OF INTEREST}

The authors declare that there are no conflicts of interest.

\section{ACKNOWLEDGEMENTS}

The authors would like to thank all subjects who participated in this study. This study was supported by National Institutes of Health (NIH) awards HL077450, HL076434, HL107715 and NIH/NCATS UL1 TR001082. Dr. Dow was supported by NIH T32 HL007822. 


\section{REFERENCES}

Campia, U., Tesauro, M. and Cardillo, C. 2012. Human obesity and endotheliumdependent responsiveness. Br J Pharmacol. 165(3): 561-573. doi: 10.1111/j.14765381.2011.01661.x.

Despres, J.P. and Lemieux, I. 2006. Abdominal obesity and metabolic syndrome. Nature. 444(7121): 881-887. doi: 10.1038/nature05488.

Diehl, K.J., Templeton, D.L., Ma, J., Weil, B.R., Greiner, J.J., Stauffer, B.L. and DeSouza, C.A. 2013. Impaired fasting blood glucose is associated with increased endothelin-1 vasoconstrictor tone. Atherosclerosis. 229(1): 130-133. doi: 10.1016/j.atherosclerosis.2013.04.006.

Du, T., Zhang, J., Yuan, G., Zhang, M., Zhou, X., Liu, Z., Sun, X. and Yu, X. 2015. Nontraditional risk factors for cardiovascular disease and visceral adiposity index among different body size phenotypes. Nutr Metab Cardiovasc Dis. 25(1): 100-107. doi: 10.1016/j.numecd.2014.07.006.

Ervin, R.B. 2009. Prevalence of metabolic syndrome among adults 20 years of age and over, by sex, age, race and ethnicity, and body mass index: United States, 20032006. Natl Health Stat Report. (13): 1-7. Available from http://www.ncbi.nlm.nih.gov/pubmed/19634296

Expert Panel on Detection, E. and Treatment of High Blood Cholesterol in, A. 2001. Executive Summary of The Third Report of The National Cholesterol Education Program (NCEP) Expert Panel on Detection, Evaluation, And Treatment of High Blood Cholesterol In Adults (Adult Treatment Panel III). JAMA. 285(19): 2486-2497. Available from http://www.ncbi.nlm.nih.gov/pubmed/11368702 
Fan, J., Song, Y., Chen, Y., Hui, R. and Zhang, W. 2013. Combined effect of obesity and cardio-metabolic abnormality on the risk of cardiovascular disease: a metaanalysis of prospective cohort studies. Int J Cardiol. 168(5): 4761-4768. doi: 10.1016/j.ijcard.2013.07.230.

Ghiadoni, L., Penno, G., Giannarelli, C., Plantinga, Y., Bernardini, M., Pucci, L., Miccoli, R., Taddei, S., Salvetti, A. and Del Prato, S. 2008. Metabolic syndrome and vascular alterations in normotensive subjects at risk of diabetes mellitus. Hypertension. 51(2): 440-445. doi: 10.1161/HYPERTENSIONAHA.107.103093.

Grundy, S.M. 2002. Obesity, metabolic syndrome, and coronary atherosclerosis. Circulation. 105(23): 2696-2698. doi: 10.1161/01.CIR.0000020650.86137.84

Grundy, S.M. 2004. Obesity, metabolic syndrome, and cardiovascular disease. J Clin Endocrinol Metab. 89(6): 2595-2600. doi: 10.1210/jc.2004-0372.

Han, K.A., Patel, Y., Lteif, A.A., Chisholm, R. and Mather, K.J. 2011. Contributions of dysglycaemia, obesity, and insulin resistance to impaired endotheliumdependent vasodilation in humans. Diabetes Metab Res Rev. 27(4): 354-361. doi: 10.1002/dmrr.1183.

Hoetzer, G.L., Stauffer, B.L., Greiner, J.J., Casas, Y., Smith, D.T. and DeSouza, C.A. 2003. Influence of oral contraceptive use on endothelial t-PA release in healthy premenopausal women. Am J Physiol Endocrinol Metab. 284(1): E90-95. doi: 10.1152/ajpendo.00333.2002.

Ihlemann, N., Rask-Madsen, C., Perner, A., Dominguez, H., Hermann, T., Kober, L. and Torp-Pedersen, C. 2003. Tetrahydrobiopterin restores endothelial dysfunction 
induced by an oral glucose challenge in healthy subjects. Am J Physiol Heart Circ

Physiol. 285(2): H875-882. doi: 10.1152/ajpheart.00008.2003.

Ingelsson, E., Sullivan, L.M., Murabito, J.M., Fox, C.S., Benjamin, E.J., Polak, J.F., Meigs, J.B., Keyes, M.J., O'Donnell, C.J., Wang, T.J., D'Agostino, R.B., Sr., Wolf, P.A. and Vasan, R.S. 2007. Prevalence and prognostic impact of subclinical cardiovascular disease in individuals with the metabolic syndrome and diabetes.

Diabetes. 56(6): 1718-1726. doi: 10.2337/db07-0078.

Lohman, T.G., Roche, A.F. and Mortorelli, R. 1988. Anthropometric Standardization Reference Manual. Champaign, IL, Human Kinetics.

Matthews, D.R., Hosker, J.P., Rudenski, A.S., Naylor, B.A., Treacher, D.F. and Turner, R.C. 1985. Homeostasis model assessment: insulin resistance and beta-cell function from fasting plasma glucose and insulin concentrations in man. Diabetologia. 28(7): 412-419. Available from http://www.ncbi.nlm.nih.gov/pubmed/3899825

Mottillo, S., Filion, K.B., Genest, J., Joseph, L., Pilote, L., Poirier, P., Rinfret, S., Schiffrin, E.L. and Eisenberg, M.J. 2010. The metabolic syndrome and cardiovascular risk a systematic review and meta-analysis. J Am Coll Cardiol. 56(14): 1113-1132. doi: 10.1016/j.jacc.2010.05.034.

Park, Y.W., Zhu, S., Palaniappan, L., Heshka, S., Carnethon, M.R. and Heymsfield, S.B. 2003. The metabolic syndrome: prevalence and associated risk factor findings in the US population from the Third National Health and Nutrition Examination Survey, 1988-1994. Arch Intern Med. 163(4): 427-436. doi, http://www.ncbi.nlm.nih.gov/pubmed/12588201 
Plavnik, F.L., Ajzen, S.A., Christofalo, D.M., Barbosa, C.S. and Kohlmann, O., Jr. 2007. Endothelial function in normotensive and high-normal hypertensive subjects. J Hum Hypertens. 21(6): 467-472. doi: 10.1038/sj.jhh.1002164.

Quyyumi, A.A. 1998. Endothelial function in health and disease: new insights into the genesis of cardiovascular disease. Am J Med. 105(1A): 32S-39S.

Rocha, N.G., Templeton, D.L., Greiner, J.J., Stauffer, B.L. and DeSouza, C.A. 2014. Metabolic syndrome and endothelin-1 mediated vasoconstrictor tone in overweight/obese adults. Metabolism. 63(7): 951-956. doi: 10.1016/j.metabol.2014.04.007.

Schinzari, F., Tesauro, M., Rovella, V., Galli, A., Mores, N., Porzio, O., Lauro, D. and Cardillo, C. 2010. Generalized impairment of vasodilator reactivity during hyperinsulinemia in patients with obesity-related metabolic syndrome. Am J Physiol Endocrinol Metab. 299(6): E947-952. doi: 10.1152/ajpendo.00426.2010.

Schinzari, F., Tesauro, M., Rovella, V., Di Daniele, N., Mores, N., Veneziani, A. and Cardillo, C. 2013. Leptin stimulates both endothelin-1 and nitric oxide activity in lean subjects but not in patients with obesity-related metabolic syndrome. J Clin Endocrinol Metab. 98(3): 1235-1241. doi: 10.1210/jc.2012-3424.

Schinzari, F., Iantorno, M., Campia, U., Mores, N., Rovella, V., Tesauro, M., Di Daniele, N. and Cardillo, C. 2015. Vasodilator responses and endothelin-dependent vasoconstriction in metabolically healthy obesity and the metabolic syndrome. Am J Physiol Endocrinol Metab. 309(9): E787-792. doi: 10.1152/ajpendo.00278.2015.

Suzuki, T., Hirata, K., Elkind, M.S., Jin, Z., Rundek, T., Miyake, Y., BodenAlbala, B., Di Tullio, M.R., Sacco, R. and Homma, S. 2008. Metabolic syndrome, 
endothelial dysfunction, and risk of cardiovascular events: the Northern Manhattan Study (NOMAS). Am Heart J. 156(2): 405-410. doi: 10.1016/j.ahj.2008.02.022.

Tesauro, M., Schinzari, F., Iantorno, M., Rizza, S., Melina, D., Lauro, D. and Cardillo, C. 2005. Ghrelin improves endothelial function in patients with metabolic syndrome. Circulation. 112(19): 2986-2992. doi:

10.1161/CIRCULATIONAHA.105.553883.

Van Guilder, G.P., Stauffer, B.L., Greiner, J.J. and Desouza, C.A. $2008 a$. Impaired endothelium-dependent vasodilation in overweight and obese adult humans is not limited to muscarinic receptor agonists. Am J Physiol Heart Circ Physiol. 294(4): H1685-1692. doi: 10.1152/ajpheart.01281.2007.

Van Guilder, G.P., Hoetzer, G.L., Greiner, J.J., Stauffer, B.L. and DeSouza, C.A. 2008b. Metabolic syndrome and endothelial fibrinolytic capacity in obese adults. Am J Physiol Regul Integr Comp Physiol. 294(1): R39-44. doi: 10.1152/ajpregu.00564.2007.

Vehkavaara, S., Seppala-Lindroos, A., Westerbacka, J., Groop, P.H. and YkiJarvinen, H. 1999. In vivo endothelial dysfunction characterizes patients with impaired fasting glucose. Diabetes Care. 22(12): 2055-2060. doi: 10.2337/diacare.22.12.2055.

Weil, B.R., Stauffer, B.L., Greiner, J.J. and DeSouza, C.A. 2011. Prehypertension is associated with impaired nitric oxide-mediated endothelium-dependent vasodilation in sedentary adults. Am J Hypertens. 24(9): 976-981. doi: 10.1038/ajh.2011.88.

Weil, B.R., Westby, C.M., Greiner, J.J., Stauffer, B.L. and DeSouza, C.A. 2012. Elevated endothelin-1 vasoconstrictor tone in prehypertensive adults. Can J Cardiol. 28(3): 347-353. doi: 10.1016/j.cjca.2011.11.006. 
Yasue, H., Matsuyama, K., Matsuyama, K., Okumura, K., Morikami, Y. and Ogawa, H. 1990. Responses of angiographically normal human coronary arteries to intracoronary injection of acetylcholine by age and segment. Possible role of early coronary atherosclerosis. Circulation. 81(2): 482-490. doi: 10.1161/01.CIR.81.2.482.

Yoo, H.J., Hwang, S.Y., Hong, H.C., Choi, H.Y., Seo, J.A., Kim, S.G., Kim, N.H., Choi, D.S., Baik, S.H. and Choi, K.M. 2014. Association of metabolically abnormal but normal weight (MANW) and metabolically healthy but obese (MHO) individuals with arterial stiffness and carotid atherosclerosis. Atherosclerosis. 234(1): 218-223. doi: 10.1016/j.atherosclerosis.2014.02.033.

Yoo, H.J., Kim, S., Hwang, S.Y., Hong, H.C., Choi, H.Y., Seo, J.A., Kim, S.G., Kim, N.H., Choi, D.S., Baik, S.H. and Choi, K.M. 2015. Vascular inflammation in metabolically abnormal but normal-weight and metabolically healthy obese individuals analyzed with (18)f-fluorodeoxyglucose positron emission tomography. Am J Cardiol. 115(4): 523-528. doi: 10.1016/j.amjcard.2014.11.036. 
TABLES

Table. Selected subject characteristics

\begin{tabular}{lccc}
\hline & $\begin{array}{c}\text { Normal Weight } \\
\text { Variable }\end{array}$ & $\begin{array}{c}\text { Normal Weight }+ \\
\text { MetS } \\
(\mathrm{n}=11)\end{array}$ & Obese \\
& & & \\
\hline Age (years) & $55 \pm 11)$ & $56 \pm 3$ & $56 \pm 2$ \\
Body mass $(\mathrm{kg})$ & $75.0 \pm 3.1$ & $79.7 \pm 2.1$ & $94.7 \pm 3.9^{* \dagger}$ \\
BMI $\left(\mathrm{kg} / \mathrm{m}^{2}\right)$ & $24.0 \pm 0.3$ & $24.7 \pm 0.3$ & $31.4 \pm .0 .5^{* \dagger}$ \\
Body fat $(\%)$ & $25.5 \pm 2.0$ & $27.2 \pm 1.6$ & $36.3 \pm 2.1^{*} \dagger$ \\
Waist circumference $(\mathrm{cm})$ & $85.6 \pm 2.8$ & $89.6 \pm 2.4$ & $105.3 \pm 2.6^{*} \dagger$ \\
Systolic BP $(\mathrm{mmHg})$ & $113 \pm 2$ & $129 \pm 3^{*}$ & $128 \pm 2^{*}$ \\
Diastolic BP $(\mathrm{mmHg})$ & $74 \pm 3$ & $78 \pm 2$ & $81 \pm 1^{*}$ \\
Total cholesterol $(\mathrm{mg} / \mathrm{dL})$ & $176.7 \pm 5.5$ & $190.6 \pm 8.5$ & $187.9 \pm 16.8$ \\
HDL cholesterol $(\mathrm{mg} / \mathrm{dL})$ & $49.0 \pm 3.9$ & $39.5 \pm 2.1^{*}$ & $47.6 \pm 2.1$ \\
LDL cholesterol $(\mathrm{mg} / \mathrm{dL})$ & $110.3 \pm 6.9$ & $115.3 \pm 6.8$ & $121.6 \pm 14.4$ \\
Triglyerides $(\mathrm{mg} / \mathrm{dL})$ & $87.5 \pm 7.2$ & $195.5 \pm 21.0^{*}$ & $93.8 \pm 10.9 \dagger$ \\
Glucose $(\mathrm{mg} / \mathrm{dL})$ & $89.5 \pm 2.1$ & $103.6 \pm 4.3^{*}$ & $92.8 \pm 3.0 \dagger$ \\
Insulin $(\mu \mathrm{U} / \mathrm{L})$ & $5.1 \pm 0.8$ & $6.8 \pm 0.6$ & $8.2 \pm 1.0^{*}$ \\
HOMA-IR & $1.1 \pm 0.2$ & $1.7 \pm 0.2^{*}$ & $2.1 \pm 0.3^{*}$ \\
\hline
\end{tabular}

BMI, body mass index; BP, blood pressure; HDL, high-density lipoprotein; LDL, lowdensity lipoprotein; HOMA-IR, homeostasis model of insulin resistance.

Values are mean \pm SEM.

$* \mathrm{P}<0.05$ vs normal weight

$\dagger \mathrm{P}<0.05$ vs normal weight + MetS 


\section{FIGURE LEGENDS}

Figure 1. FBF responses (panel A) and total FBF (area under the curve; panel B) to acetylcholine and FBF responses to sodium nitroprusside (panel C) in the normal weight adults, normal weight adults with MetS and obese groups. Values are mean \pm SEM. $* \mathrm{P}<0.05$ vs. normal weight.

Figure 2. Correlations between peak FBF response to acetylcholine and glucose (panel A) and systolic blood pressure (panel B) in normal weight subjects (with and without MetS). 

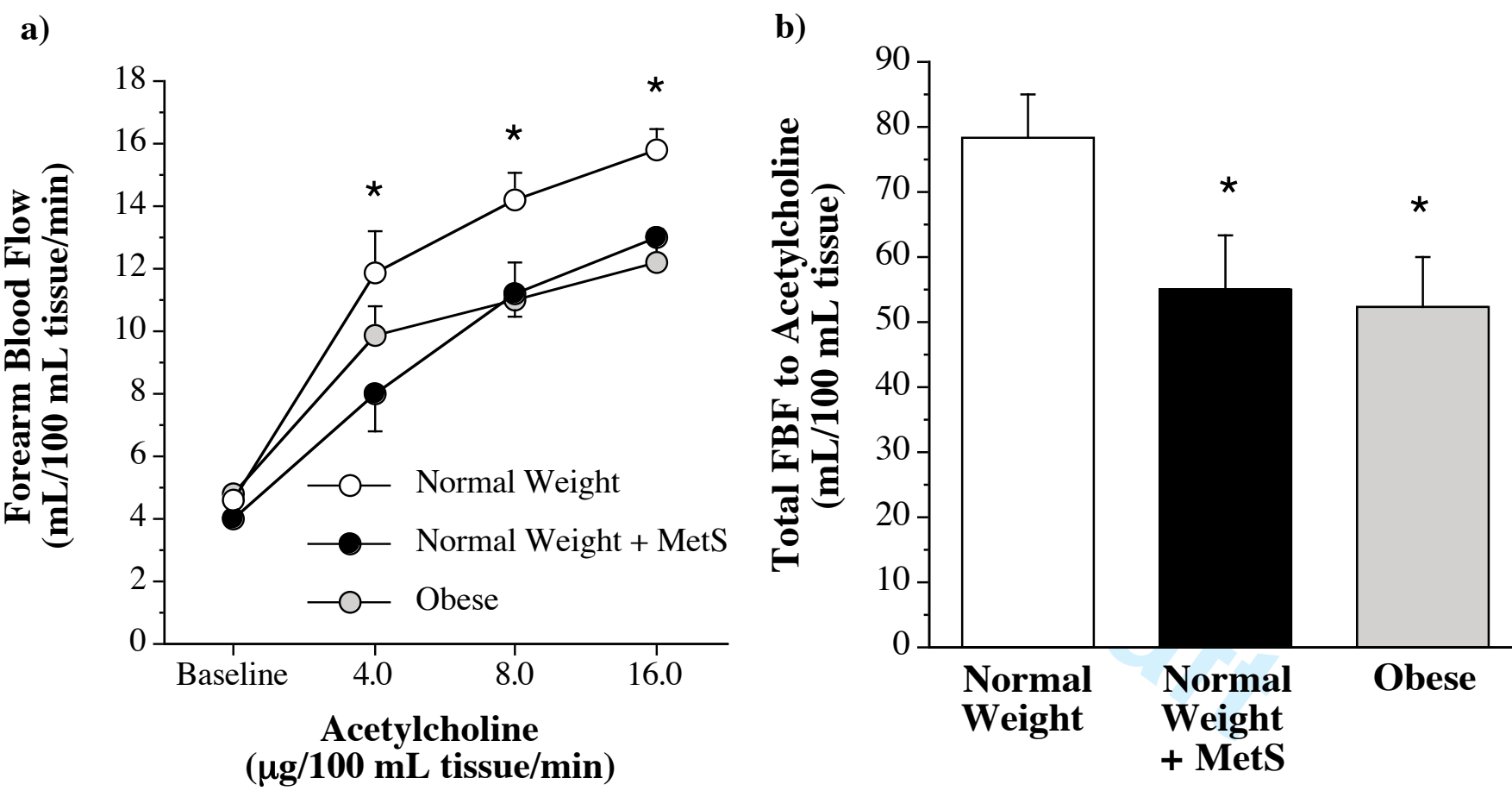

c)

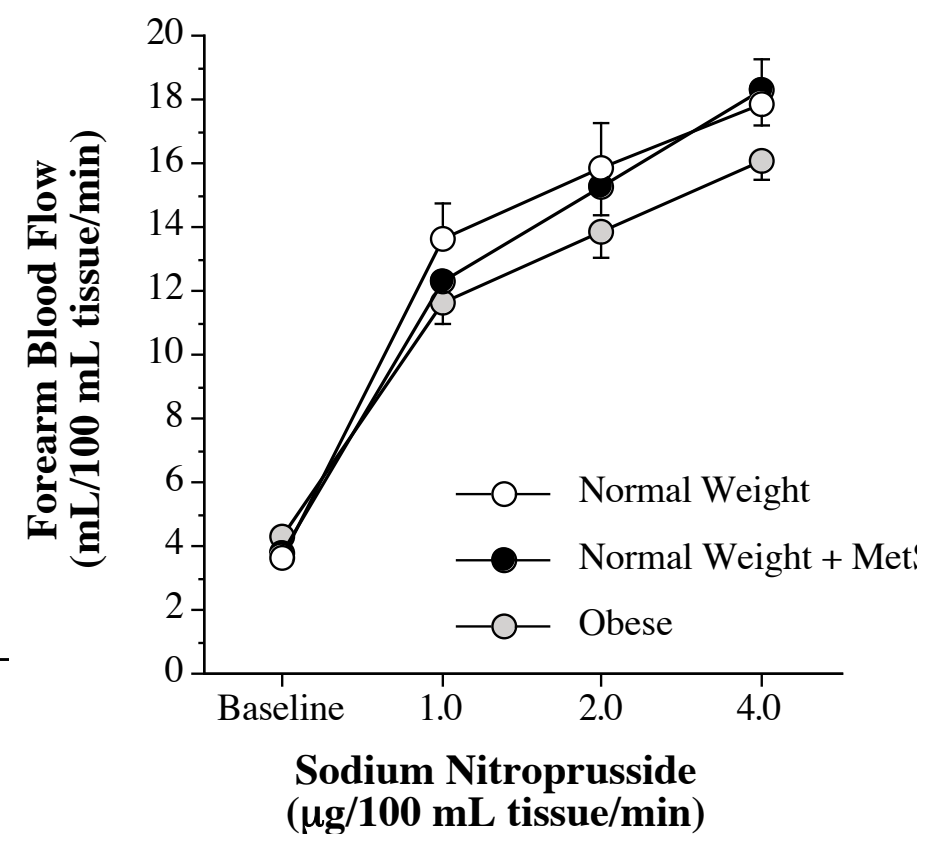


a)

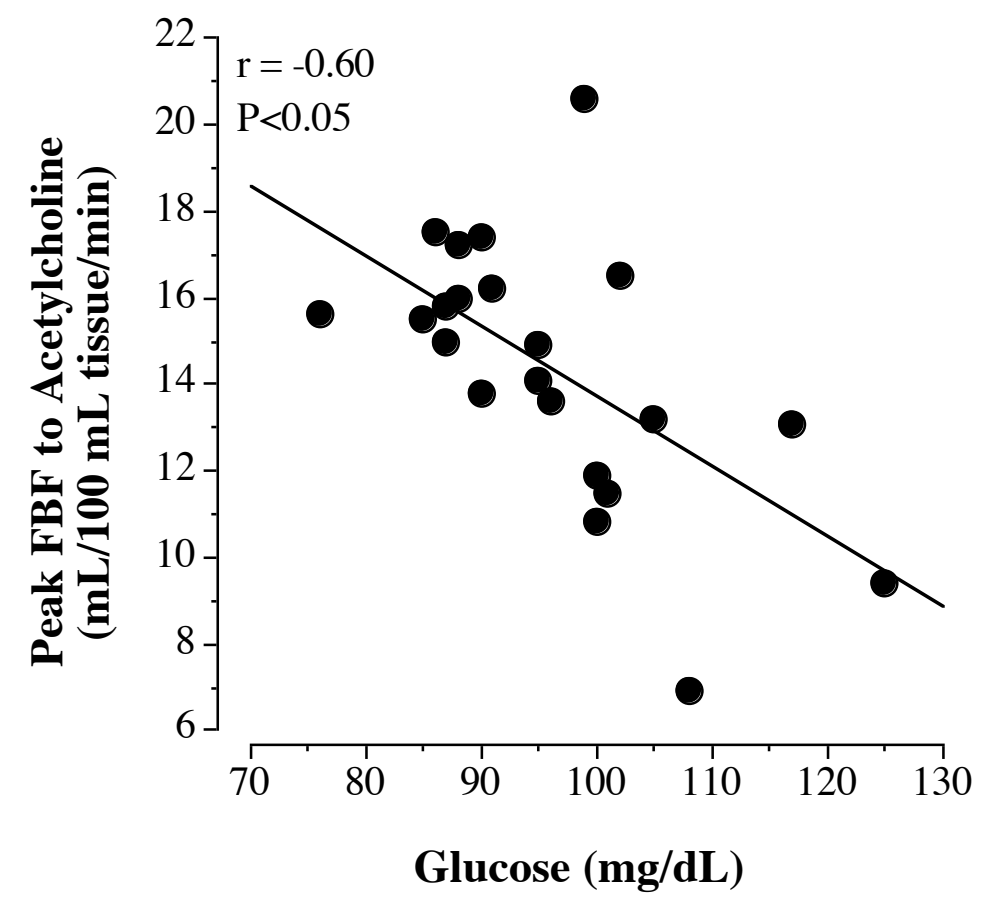

b)

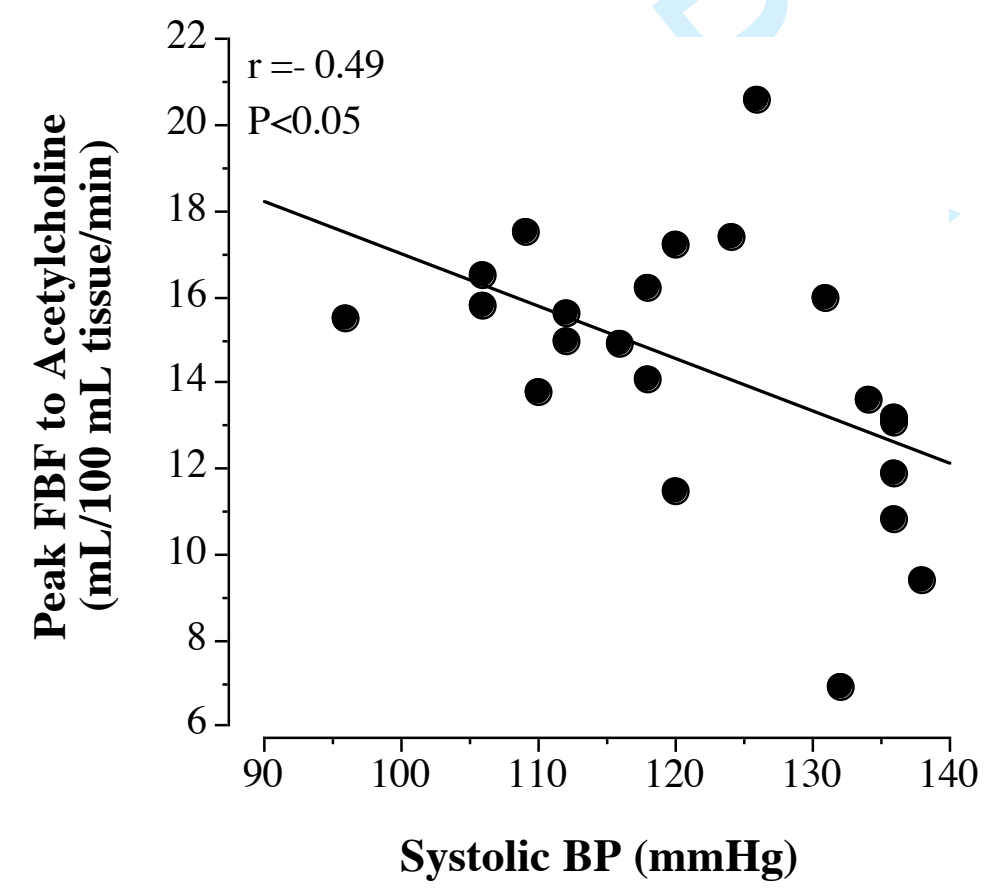

